\title{
LA ACCIÓN GEOMORFOLÓGICA DEL MANTO NIVOSO ESTACIONAL EN LA SIERRA DE ANCARES: VERTIENTE NORORIENTAL DEL PICO CUIÑA (LEÓN)
}

\author{
P. CARRERA GÓMEZ y M. VALCÁRCEL DÍAZ \\ Departamento de Xeografía, Universidade de Santiago de Compostela, \\ Praza da Universidade, 1. 15782-Santiago de Compostela (A Coruña) \\ Correo electrónico de contacto: marcos.valcarcel@usc.es
}

\begin{abstract}
RESUMEN. En este trabajo se describe la actividad geomorfológica del manto nivoso estacional en un sector de la vertiente nororiental del Pico Cuiña, Sierra de Ancares. El desplazamiento en masa de la nieve arranca y moviliza fragmentos del substrato rocoso, depositándolos al pie de la vertiente. Esta actividad produce una serie de formas características: superficies pulidas, estrías, acanaladuras, fracturas arqueadas, microcrestas y morrenas de nevero. En el desplazamiento en masa del manto nivoso intervienen tanto movimientos de tipo rápido (avalanchas de fondo) como lento (deslizamiento nival).
\end{abstract}

ABSTRACT. The geomophic action of the seasonal snow cover on the northeastern slope of Pico Cuiña (Sierra de Ancares, León province), is described. Mass movement of the snow is responsible for the quarrying of bedrock and the transport of loose clasts to the lower margins of the slope. Such geomorphic activity gives rise to a set of characteristic geoforms such as smoothed surfaces, striae, grooves, crescentic fractures, micro-ridges and protalus ramparts. Mass displacement of the snow cover comprises both fast (full-depth avalanches) and slow (snowslide) movements.

Palabras clave: manto nivoso estacional, erosión nival, avalancha, deslizamiento nival, Sierra de Ancares.

Key words: seasonal snow cover, nival erosion, avalanche, snowslide, Sierra de Ancares.

Enviado el 15 de octubre de 2009 Aceptado el 18 de febrero de 2010

\section{Introducción}

El manto nivoso estacional desempeña un papel determinante en la evolución morfológica actual de las vertientes rocosas de los sectores culminantes de la Sierra de 


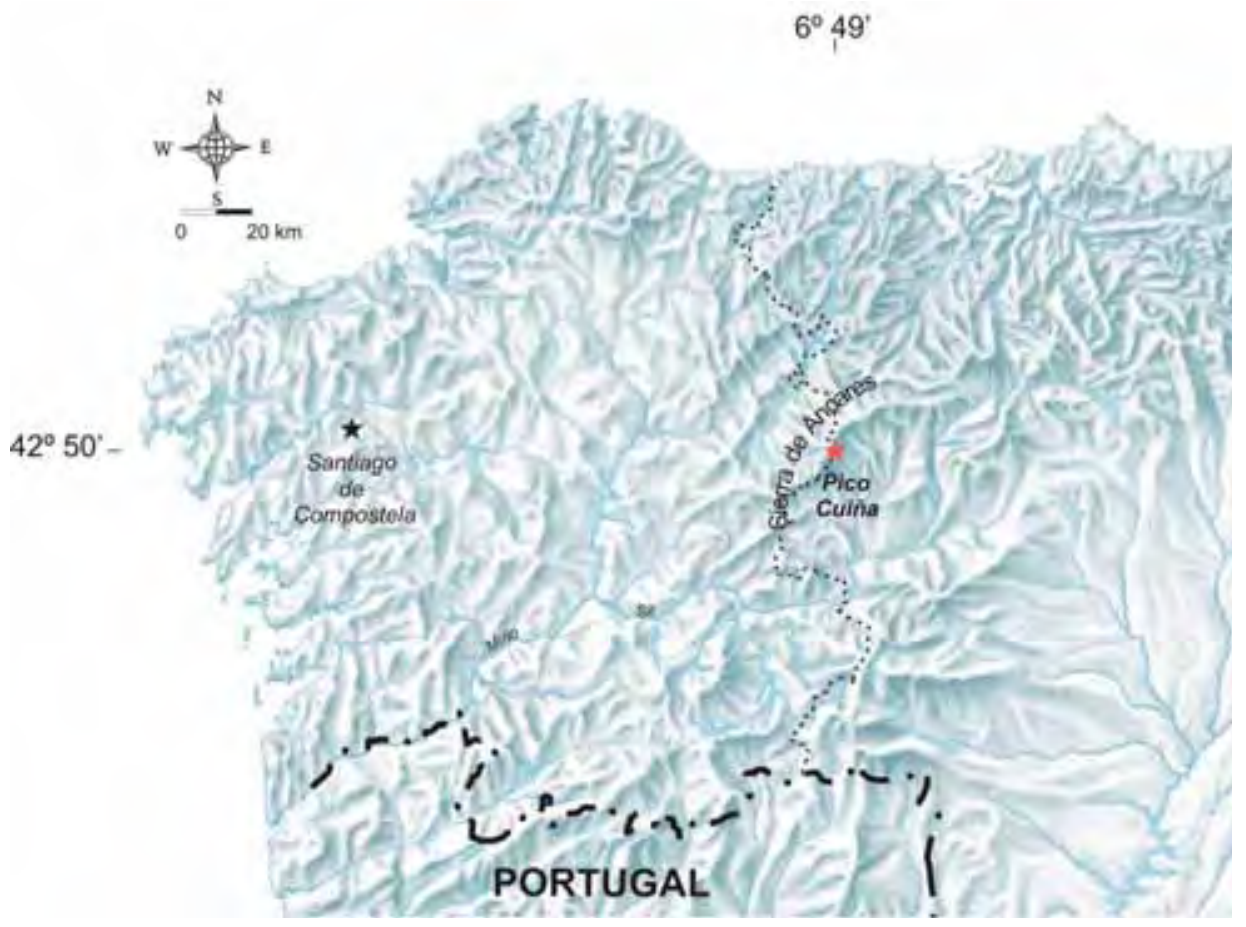

Figura 1. Localización del área de estudio en el noroeste de la Península Ibérica.

Ancares (NO de la Península Ibérica). En el presente trabajo se describe la acción geomorfológica de la nieve observada en la vertiente nororiental del pico Cuiña, cabecera del río Ancares, León (latitud 42 $50^{\prime} \mathrm{N}$; longitud 6 49' O; altitud 1.875 m.s.n.m.) (Figs. 1 y 2), prestando particular atención a la caracterización de las geoformas de erosión y acumulación originadas, así como a los procesos implicados en su génesis.

Este sector de la Sierra está formado por pizarras y cuarcitas paleozoicas de grano fino, pertenecientes a la Serie de "Los Cabos", plegadas y densamente fracturadas durante la orogenia Hercínica (Pulgar et al., 1978). La cabecera del río Ancares constituye un amplio anfiteatro glaciar de cerca de 1,5 km de ancho, delimitado por aristas que culminan en los picos Cuiña (1.992 m.s.n.m.) y Dos Hermanitos (1.901 m.s.n.m.). Se trata de un circo escalonado por la sucesión de tres grandes umbrales transversales, en los que abundan las rocas aborregadas y las superficies pulidas (Valcárcel Díaz, 1998; Valcárcel Díaz y Pérez Alberti, 2002). La actividad crionival actual en el ámbito del circo se evidencia además por la presencia de suelos ordenados, lóbulos de solifluxión y bloques aradores (Valcárcel Díaz, 1998).

La vertiente estudiada presenta una disposición topográfica escalonada. Está formada por una sucesión de rellanos subhorizontales, superficies de pendiente moderada 


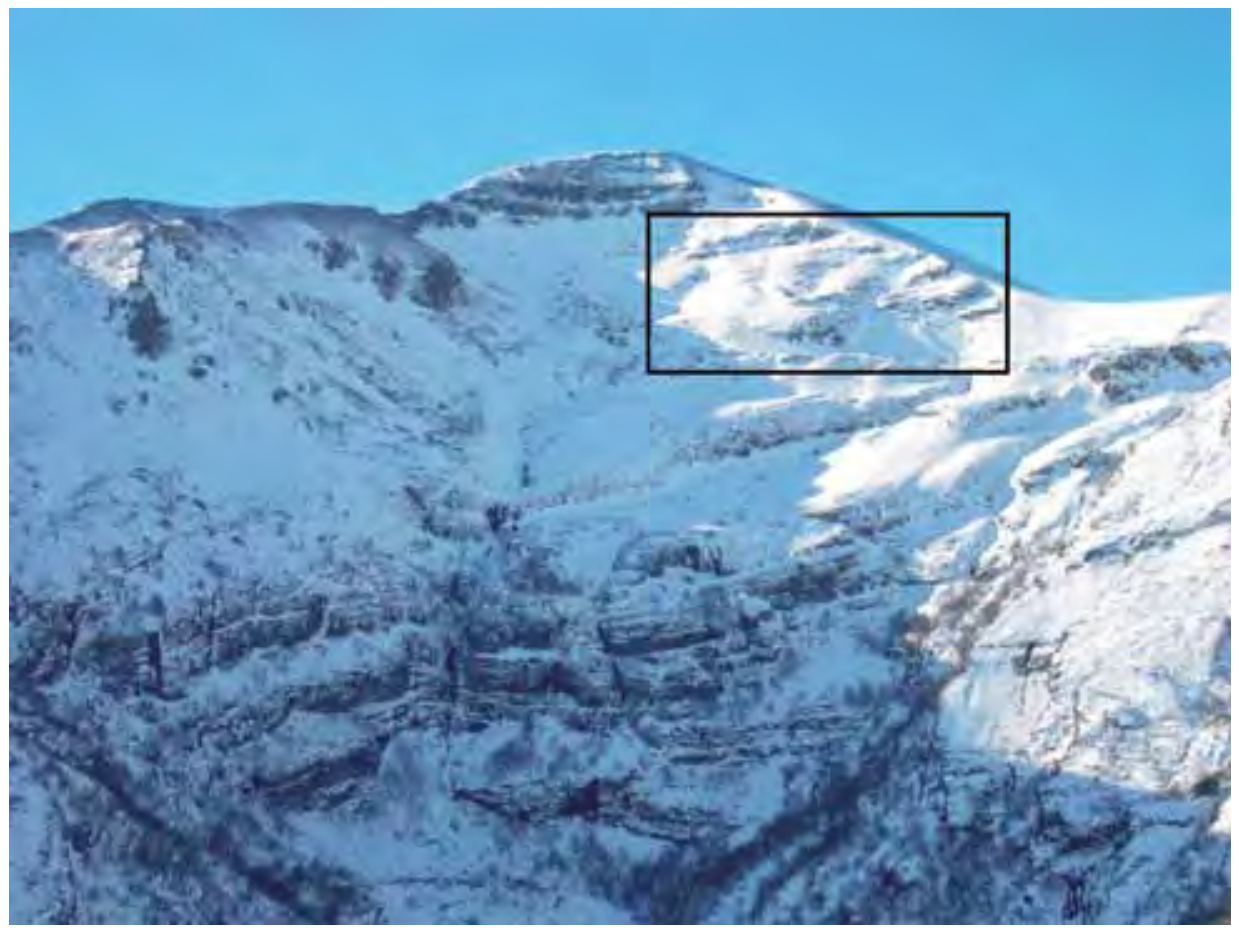

Figura 2. Vertiente nororiental del Pico Cuiña. El recuadro delimita el sector reconocido.

y pequeñas paredes subverticales, cortados en el extremo occidental por un canal que sigue una línea de falla.

En las inmediaciones del área reconocida, a una altitud de 1.870 m.s.n.m., se ha obtenido un registro de temperatura del aire que comprende el invierno y la primavera meteorológicos de 2003. La temperatura media del invierno (meses de diciembre a febrero) fue $-1,3{ }^{\circ} \mathrm{C}$, y las temperaturas mínima y máxima absolutas fueron $-12,2{ }^{\circ} \mathrm{C}$ y $8,4{ }^{\circ} \mathrm{C}$ respectivamente. Durante la primavera (meses de marzo a mayo) la temperatura media fue $3,8{ }^{\circ} \mathrm{C}$, registrándose unas temperaturas mínima y máxima absolutas de $-5,4{ }^{\circ} \mathrm{C}$ y $19,9^{\circ} \mathrm{C}$ respectivamente. La estación pluviométrica más cercana es “Tejedo de Ancares". Está situada a 990 m.s.n.m. en el valle del río Ancares, a $11 \mathrm{~km}$ al E de la zona de estudio. Según Penas Merino et al. (1995) en esta estación y para un período de observación no especificado, se registra una precipitación media anual de $2.022 \mathrm{~mm}$. Se desconoce el gradiente pluviométrico en este sector de la Sierra, por lo que no es posible hacer una estimación de los valores de precipitación registrados en los niveles culminantes. Tampoco se conoce el porcentaje que supone la aportación de la nieve al volumen total anual de precipitación.

La cubierta vegetal es escasa, predominando las superficies de roca colonizadas parcialmente por líquenes crustáceos del género Rhizocarpon. Al pie de las paredes y 
rellanos rocosos se han formado suelos someros, mayoritariamente colonizados por Vaccinium uliginosum y Calluna vulgaris.

\section{Características del manto nivoso estacional}

Bajo las actuales condiciones climáticas la cubierta nivosa presenta una duración irregular. En años nivosos suele establecerse a comienzos de noviembre, desapareciendo sus últimos retazos a mediados de julio. Por el contrario, en años caracterizados por la escasez de precipitaciones, su formación puede retrasarse hasta diciembre y la fusión total se produce en mayo.

El espesor varía considerablemente de unos lugares a otros, debido a la redistribución de la nieve por el viento, así como a la topografía irregular del terreno. En el borde del circo se originan potentes cornisas a partir de la nieve venteada de la vecina vertiente occidental. Es en este sector donde se alcanzan los mayores espesores, que superan con frecuencia los $4 \mathrm{~m}$.

En la primavera de 2006 se determinó la densidad de un perfil de nieve de 1,8 m de altura. Se pudo diferenciar una capa basal de $20 \mathrm{~cm}$ de espesor y $640 \mathrm{~kg} \mathrm{~m}^{-3}$ de densidad media, formada por hielo con escasas burbujas de aire, que estaba separada del substrato por una fina película de agua. El resto del perfil estaba formado por nieve metamorfizada de grano grueso, con una densidad media de $570 \mathrm{~kg} \mathrm{~m}^{-3}$.

El régimen térmico típico en la interfase manto nivoso-substrato se caracteriza por la total ausencia de variaciones y la estabilidad, prolongada a lo largo del invierno y la primavera, de la temperatura en el entorno de los $0{ }^{\circ} \mathrm{C}$. La Figura 3 muestra el registro de temperatura obtenido en el año 2004-2005, mediante un registrador automático anclado al substrato, con el elemento sensor situado a una altura de $1 \mathrm{~cm}$ sobre el suelo. Se pueden observar dos períodos de presencia del manto nivoso. En ambos la nieve alcanzó un espesor suficiente como para bloquear por completo el intercambio energético de la atmósfera con la superficie del substrato, manteniéndose ésta última a una temperatura constante de $0{ }^{\circ} \mathrm{C}$. El primer período corresponde a una cubierta nivosa poco potente y de escasa duración, propia de las primeras nevadas del año, que se extendió de finales de octubre a comienzos de noviembre. El segundo período se identifica con el verdadero manto nivoso estacional, caracterizado por su persistencia continuada. En ese año se inició a mediados de noviembre y desapareció a finales de mayo.

La cubierta nival experimenta desplazamientos en masa lentos y rápidos, responsables de la actividad geomorfológica observada. Se ha podido distinguir un movimiento en masa lento que posiblemente se corresponda con un deslizamiento nival, y que se evidencia por la formación en las cornisas de nieve del borde del circo, de grietas de tensión paralelas a las curvas de nivel. Estas fracturas suelen aparecer en enero, una vez que se alcanzan espesores máximos. El deslizamiento prosigue lentamente con el ensanchamiento progresivo de las grietas y la formación, ladera abajo, de abombamientos en la superficie del manto nivoso. La inestabilidad suele acentuarse a comienzos de la prima- 


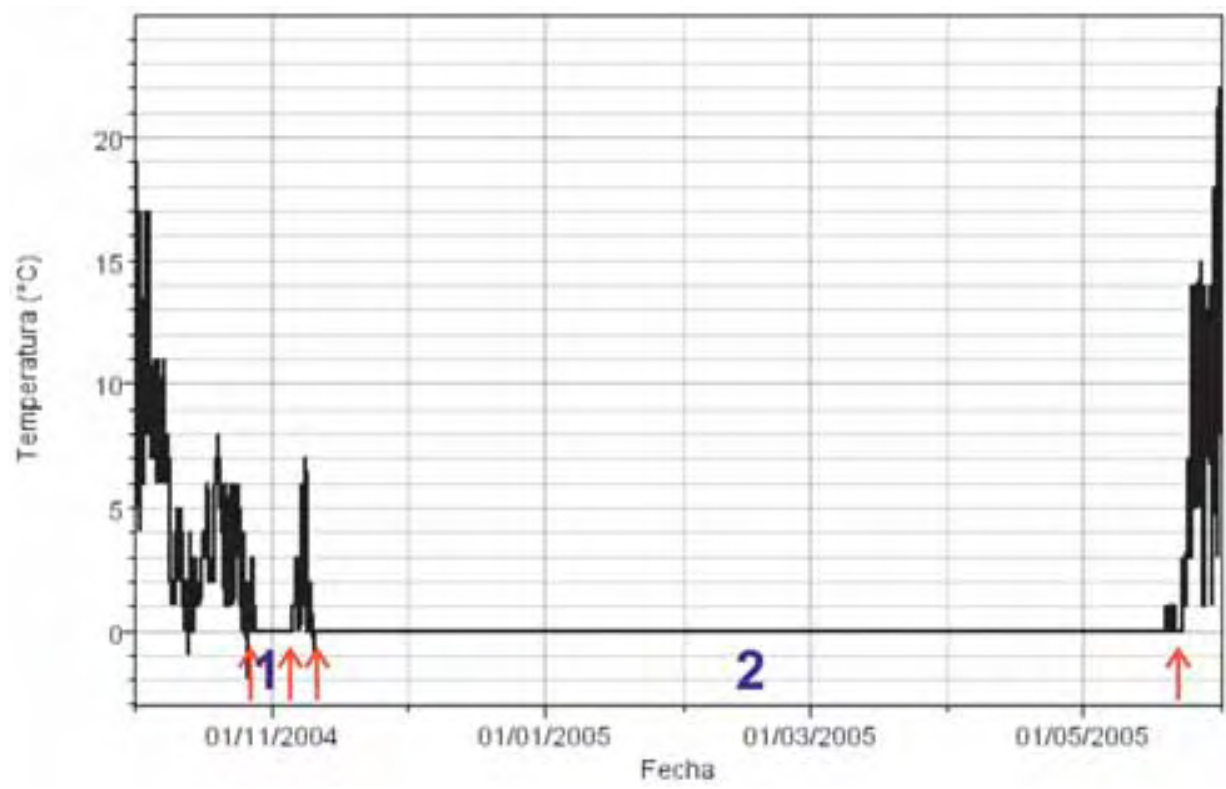

Figura 3. Evolución temporal de la temperatura en la superficie del suelo entre el 01/10/2004 y el 01/06/2005. Se registró presencia continua del manto nivoso durante los períodos 1 y 2, delimitados por flechas. En ambos períodos la gráfica representa la temperatura basal de la cubierta nivosa.

vera, dando lugar a avalanchas de fondo con recorridos de 5 a $15 \mathrm{~m}$ que ocasionan la rotura de la cubierta nival en grandes bloques. Las avalanchas suelen desencadenarse en un único evento y se producen preferentemente en canales rocosos que acumulan espesores considerables de nieve.

\section{Acción geomorfológica del manto nivoso estacional}

La actividad geomorfológica de la nieve se manifiesta por el arranque y la movilización de fragmentos del substrato, la abrasión de superficies rocosas y la deposición del material movilizado. El manto nivoso origina una serie de geoformas características, tanto de erosión (superficies pulidas, estrías, acanaladuras y fracturas arqueadas) como de acumulación (microcrestas y morrenas de nevero).

La configuración topográfica de la vertiente y el patrón de fracturación del substrato rocoso facilitan el proceso de arranque. El desalojo de los fragmentos se realiza a favor de líneas de discontinuidad preexistentes como juntas de estratificación, de esquistosidad y diaclasas. La Figura 4 muestra un bloque de pizarra situado en el borde exterior de un escalón, despegado del substrato y ligeramente desplazado ladera abajo. En este caso típico el arranque se ha producido a lo largo de un plano de estratificación, 


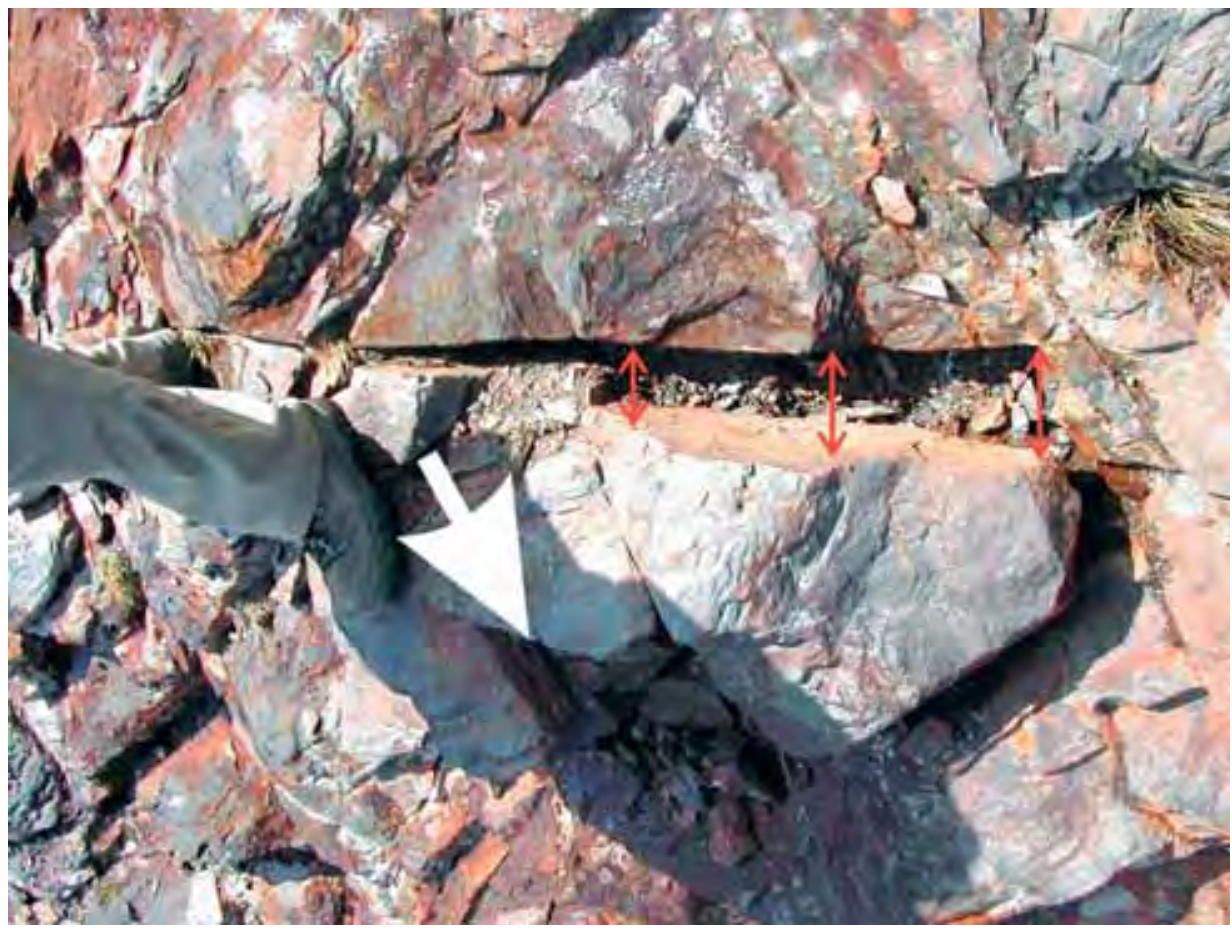

Figura 4. Despegue y desplazamiento (indicado por las flechas rojas) de un bloque de pizarra delimitado por líneas de discontinuidad. La flecha blanca indica la dirección y el sentido de desplazamiento del manto nivoso.

localizado en la base del bloque, y se ha visto favorecido por la presencia de dos planos laterales de diaclasa que delimitan el bloque. Sin embargo, en ocasiones se han observado clastos desalojados cuyos planos de rotura son completamente irregulares y no siguen por tanto, ninguno de los planos de discontinuidad estructural del macizo rocoso. El tamaño de los fragmentos arrancados es muy variado, si bien predomina la fracción bloque, no siendo infrecuentes los que superan $1 \mathrm{~m}$ de eje mayor.

Los clastos desalojados son transportados ladera abajo en la base del manto nivoso, sufriendo una progresiva desagregación debido a la fricción con el substrato y a la presión a la que son sometidos. Se generan así grandes cantidades de material detrítico heterométrico que participa en el proceso de abrasión.

La acción abrasiva de la nieve suaviza la rugosidad del substrato, originando superficies rocosas pulidas. Se encuentran en los sectores más expuestos como los planos subhorizontales de escalones y rellanos o las caras situadas "nieves arriba" de los resaltes rocosos, tanto sobre substrato cuarcítico como pizarroso. La Figura 5 muestra una superficie pulida, desarrollada sobre el plano horizontal y en el borde externo de un escalón de pizarra, cortada por numerosísimas estrías y marcas de abrasión de 


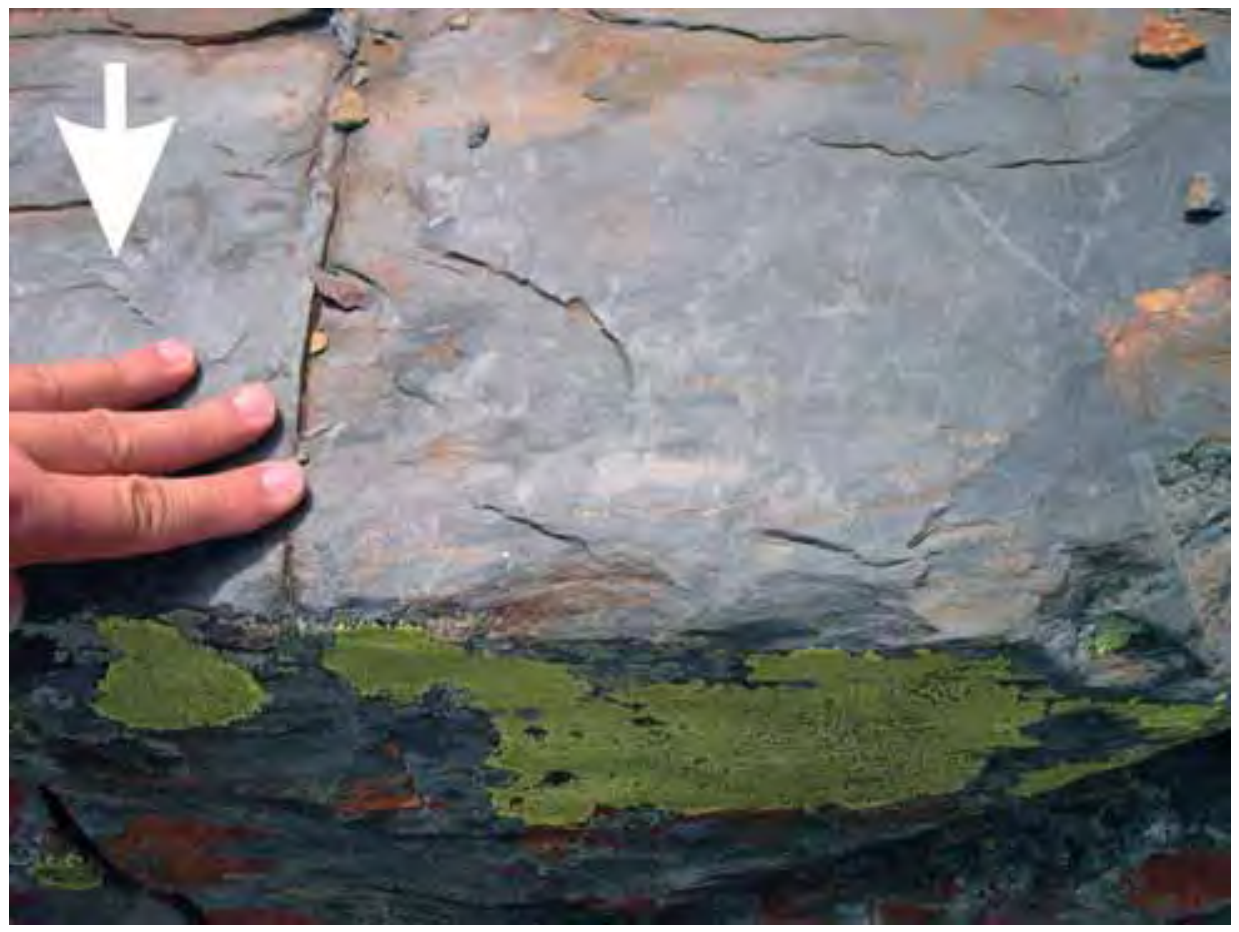

Figura 5. Detalle de una superficie pulida en el borde exterior de un escalón de pizarra. La flecha indica la dirección y el sentido del desplazamiento del manto nivoso.

tamaño diminuto. Las diferencias microtopográficas que impone la disposición de la esquistosidad de la roca han sido suavizadas parcialmente. El propio borde del escalón también ha sido desgastado. Los líquenes crustáceos han desaparecido de la superficie expuesta a la abrasión, colonizando en cambio buena parte de la cara vertical protegida del escalón.

Con mucha frecuencia las estrías acompañan a las superficies pulidas, constituyendo la microforma más abundante en la vertiente estudiada, tanto sobre substrato pizaroso como cuarcítico (Fig. 6). Se trata de incisiones rectilíneas de dimensiones muy variables, labradas sobre el substrato por el material detrítico desplazado en la base del manto nivoso. En los rellanos cuarcíticos del extremo occidental del área reconocida llegan a superar $50 \mathrm{~cm}$ de longitud y $1 \mathrm{~cm}$ de anchura. Su microtopografía es irregular y está formada por una sucesión de minúsculas fracturas arqueadas con la concavidad abierta "nieves abajo". No suelen superar los $2 \mathrm{~mm}$ de profundidad. Generalmente las estrías se alinean a grandes rasgos con la dirección de desplazamiento de la cubierta nival, si bien la disposición topográfica particular de cada afloramiento estriado impone ligeros cambios angulares a esa dirección general. 


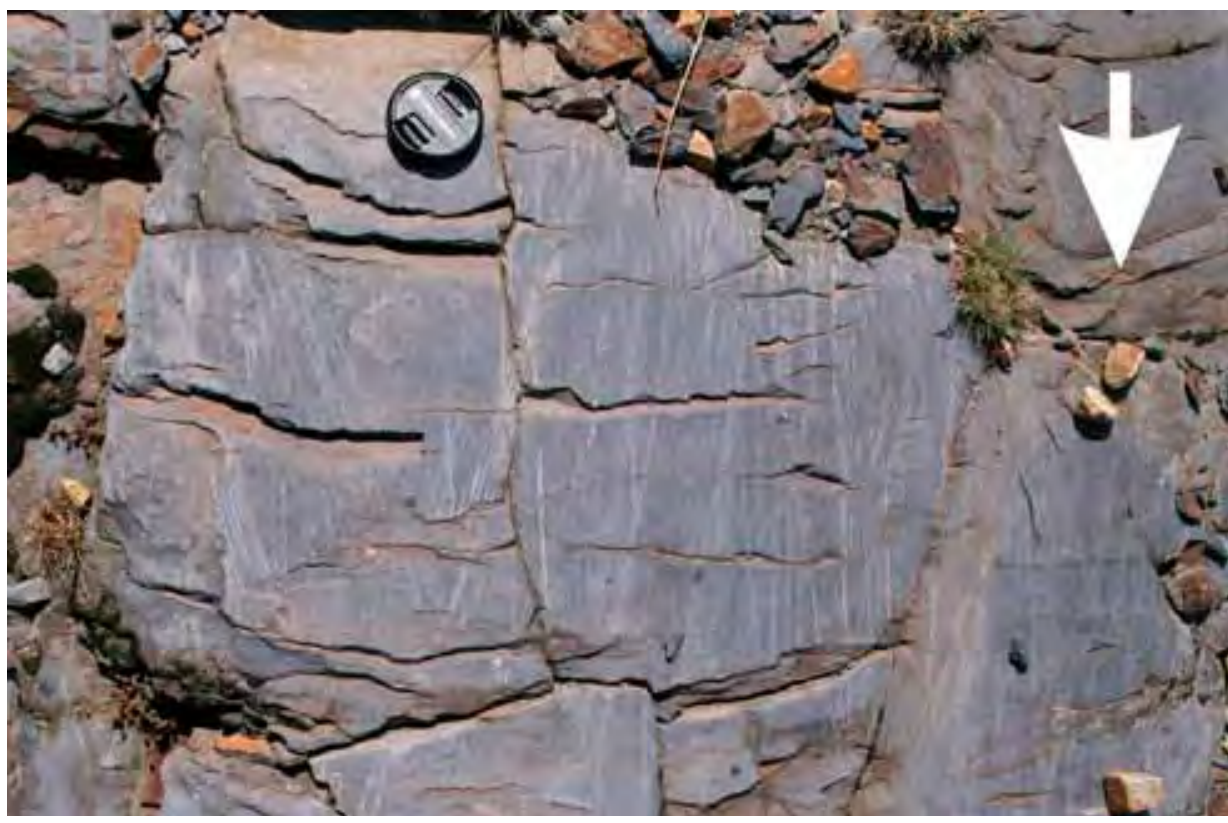

Figura 6. Estrías sobre una superficie pulida de cuarcita. La flecha indica la dirección y el sentido del desplazamiento del manto nivoso.

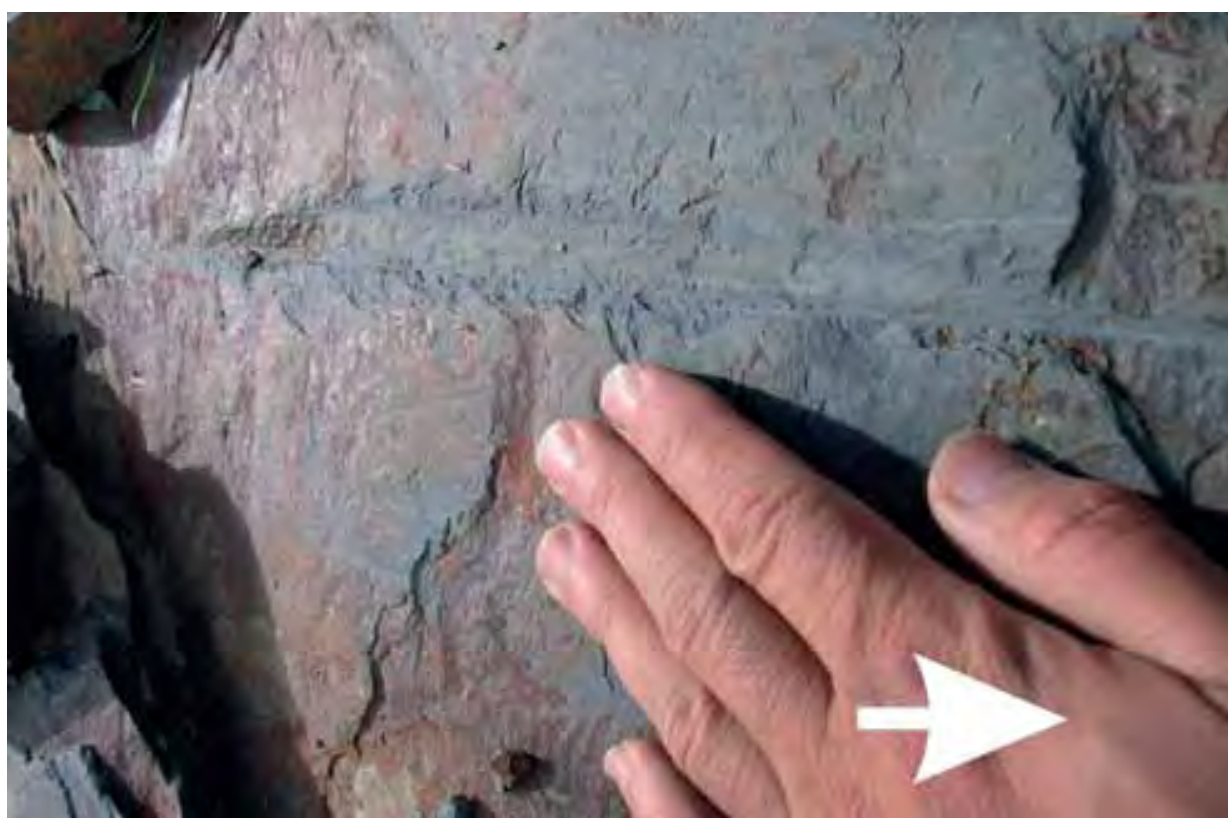

Figura 7. Ejemplo de acanaladura en una superficie de pizarra. La flecha indica la dirección y el sentido del desplazamiento del manto nivoso. 
Las acanaladuras se originan en rellanos y escalones rocosos subhorizontales de pizarra. Son depresiones rectilíneas alargadas, alineadas con la dirección de desplazamiento del manto nivoso, considerablemente más anchas y profundas que las estrías (Fig. 7), pudiendo superar $4 \mathrm{~cm}$ de anchura y $2,5 \mathrm{~cm}$ de profundidad máximas. Su desarrollo longitudinal suele interrumpirse en el margen externo de los escalones, por lo que rara vez sobrepasan $25 \mathrm{~cm}$ de longitud. Tienen un perfil transversal cóncavo, en forma de "U". Al igual que las estrías presentan un fondo y bordes laterales irregulares, formados por sucesiones de fracturas arqueadas con la concavidad abierta "nieves abajo". Las dimensiones de las acanaladuras observadas permiten suponer que la génesis de esta microforma se deba al arrastre subnival de grandes clastos.

Las fracturas arqueadas son incisiones en forma de media luna labradas en el substrato (Fig. 8). La cara cóncava de las fracturas se abre siempre "nieves abajo". Presentan un pequeño resalte subvertical, de varios $\mathrm{mm}$ de altura que define su contorno. Su anchura, considerando la distancia entre los dos extremos de la fractura, es muy variable, pudiendo en ocasiones superar los $15 \mathrm{~cm}$. Acompañan a las acanaladuras de mayor tamaño formadas sobre pizarra, presentándose agrupadas en apretada sucesión. En substrato cuarcítico aparecen aisladas. Su desarrollo parece estar relacionado con la presencia en el substrato rocoso de planos de discontinuidad (de esquistosidad en la pizarra y de estratificación en la cuarcita), que presentan una disposición paralela o subparalela a la superficie.

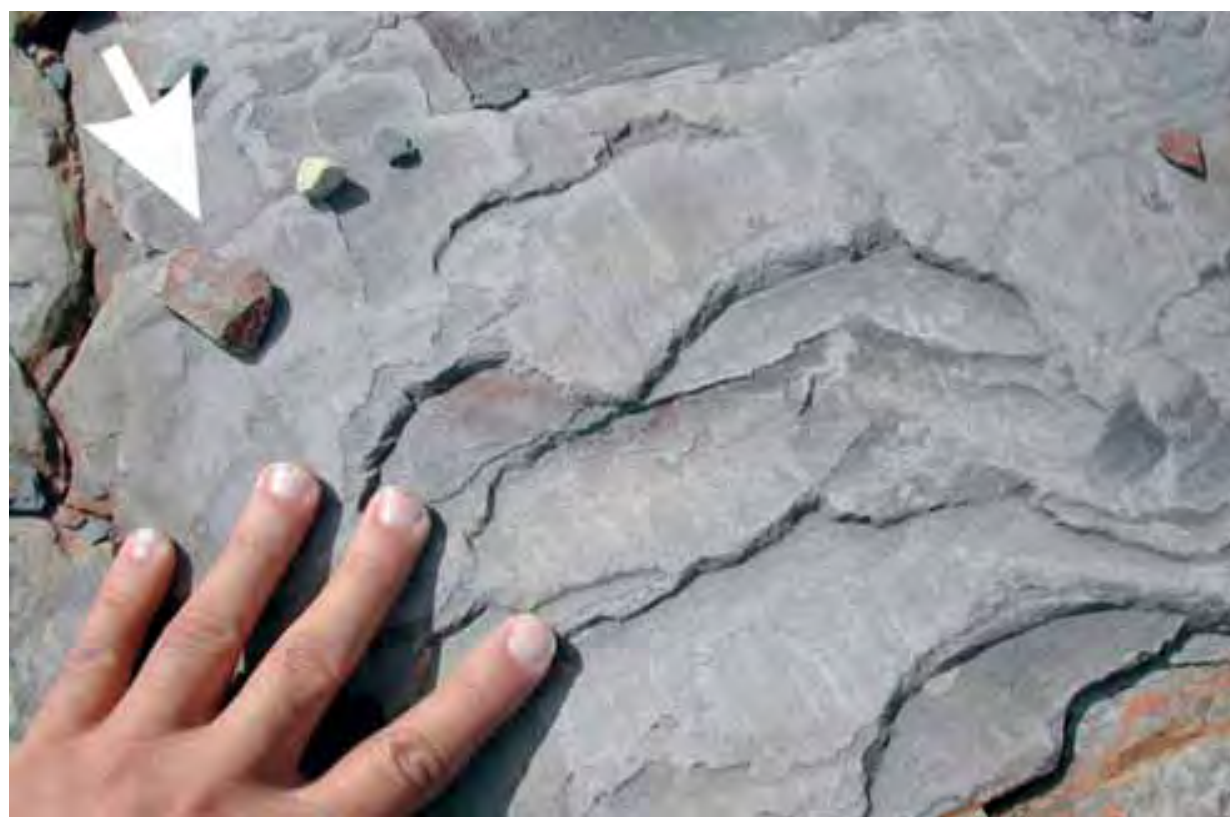

Figura 8. Fracturas arqueadas en una superficie cuarcítica. La flecha indica la dirección y el sentido del desplazamiento del manto nivoso. 
Entre las geoformas de acumulación más características que origina el empuje del manto nivoso se encuentran las microcrestas y las morrenas de nevero. Las microcrestas son pequeños caballones asimétricos, formados por material clástico heterométrico, que no suelen superar los 30-40 cm de altura y cuyo desarrollo longitudinal puede alcanzar varios m (Fig. 9). Se forman preferentemente sobre los rellanos cuarcíticos del extremo occidental del área reconocida, en sectores que reciben un suministro abundante de material clástico pizarroso, procedente de las paredes y canales situados vertiente arriba. En su composición predominan bloques y gravas. Contienen también abundantes finos que son lavados con rapidez por las aguas de fusión y de lluvia. Los clastos presentan con frecuencia caras con estrías y marcas de abrasión y bordes desgastados. En ocasiones aparecen imbricados. Las microcrestas formadas por el empuje frontal del manto nivoso tienen una forma en planta ligeramente arqueada y se disponen transversalmente a la dirección de desplazamiento de la masa de nieve (microcrestas señaladas por flechas negras en la Fig. 9). En cambio las creadas por el empuje lateral pueden ser rectilíneas o irregulares, presentando una disposición paralela o subparalela a la dirección de desplazamiento del manto nivoso (microcrestas señaladas por flechas azules en la Fig. 9). El perfil transversal de ambos tipos de microcrestas es asimétrico. La cara interna que ha sufrido el empuje de la masa de nieve tiene una pendiente más suave que la externa. Se trata de formas efímeras, que con frecuencia son destruidas, o bien notablemente modificadas, al año siguiente de su formación por los desplazamientos de la cubierta nival.

Las morrenas de nevero se han originado por un proceso de empuje similar al que crea las microcrestas, compartiendo muchas de las características de éstas y diferenciándose principalmente por su mayor tamaño. Se han distinguido tres acumulaciones morrénicas mayores, situadas en el extremo oriental del área de estudio, al pie de un tramo de ladera formado por pizarras densamente fisuradas, que suministra gran cantidad de material clástico (Fig. 10). Dos de las morrenas se disponen transversalmente a la dirección de empuje del manto nivoso, presentando una posición frontal y una forma en planta ligeramente arqueada (acumulaciones señaladas por flechas azules y rojas en la Fig. 10). La tercera tiene una posición frontolateral, disponiéndose subparalela a la dirección de desplazamiento del manto nivoso en su tramo superior, y transversal a ésta en su tramo inferior, donde presenta una forma en planta arqueada (morrena señalada por flechas negras en la Fig. 10). Llegan a alcanzar una altura y anchura máximas de 1,7 y 3 m respectivamente. La acumulación frontolateral supera los $10 \mathrm{~m}$ de desarrollo longitudinal. Su perfil transversal es asimétrico. Las caras internas (orientadas "nieves arriba") tienen una pendiente más suave las externas (orientadas "nieves abajo"). Las morrenas frontales están compuestas por un diamicton matrizsoportado con abundantes finos. En cambio, el tramo lateral de la morrena frontolateral está formado mayoritariamente por bloques con estructura abierta. En todas las acumulaciones los clastos suelen presentar aristas desgastadas y caras con marcas de abrasión y estrías. La acción de empuje del manto nivoso se evidencia en las caras internas de las morrenas frontales, donde son frecuentes los bloques embutidos en la matriz de finos por la presión de la nieve. El empuje nival ha modificado la cresta de la morrena frontolateral en su extremo inferior, creando una superficie aplanada con clastos enrasados en la matriz de finos. Las caras internas aparecen desprovistas de 


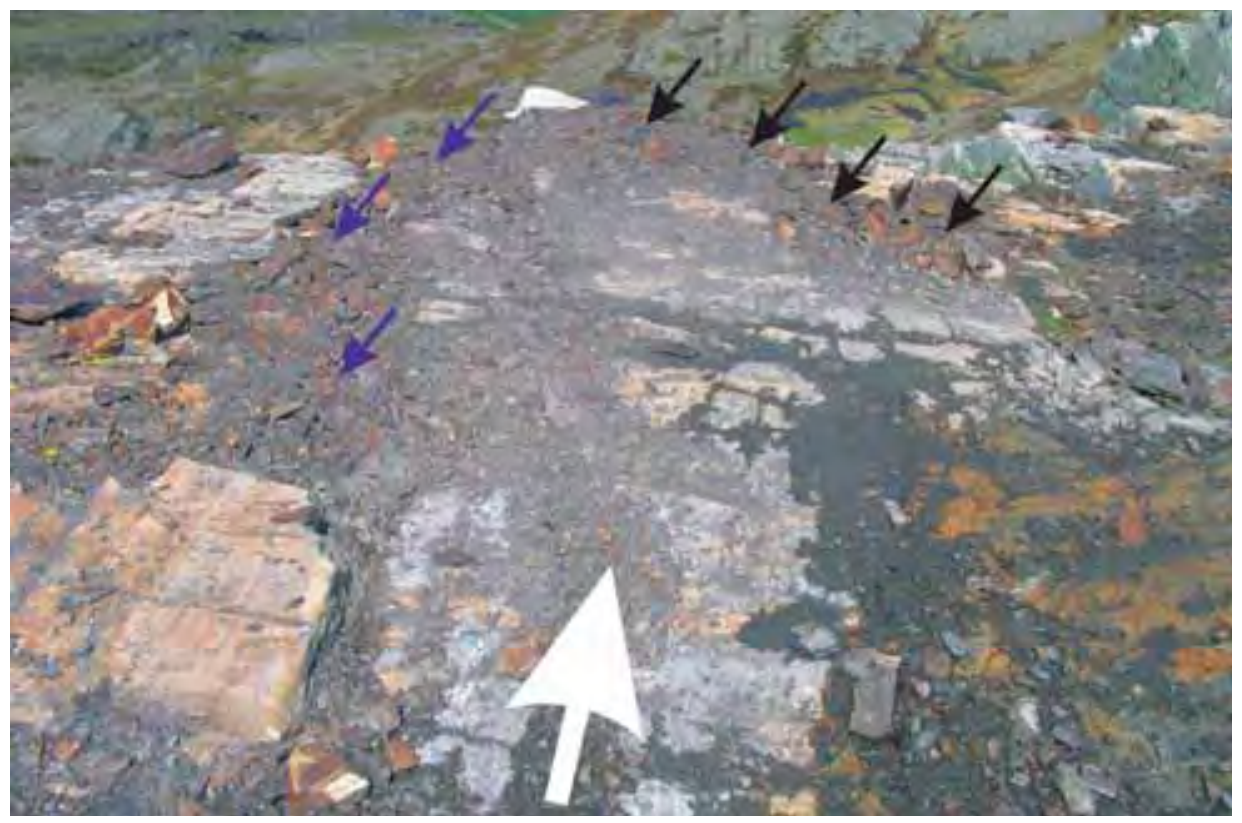

Figura 9. Ejemplos de microcrestas frontales (flechas negras) y laterales (flechas azules). La flecha blanca indica la dirección y el sentido del desplazamiento del manto nivoso.

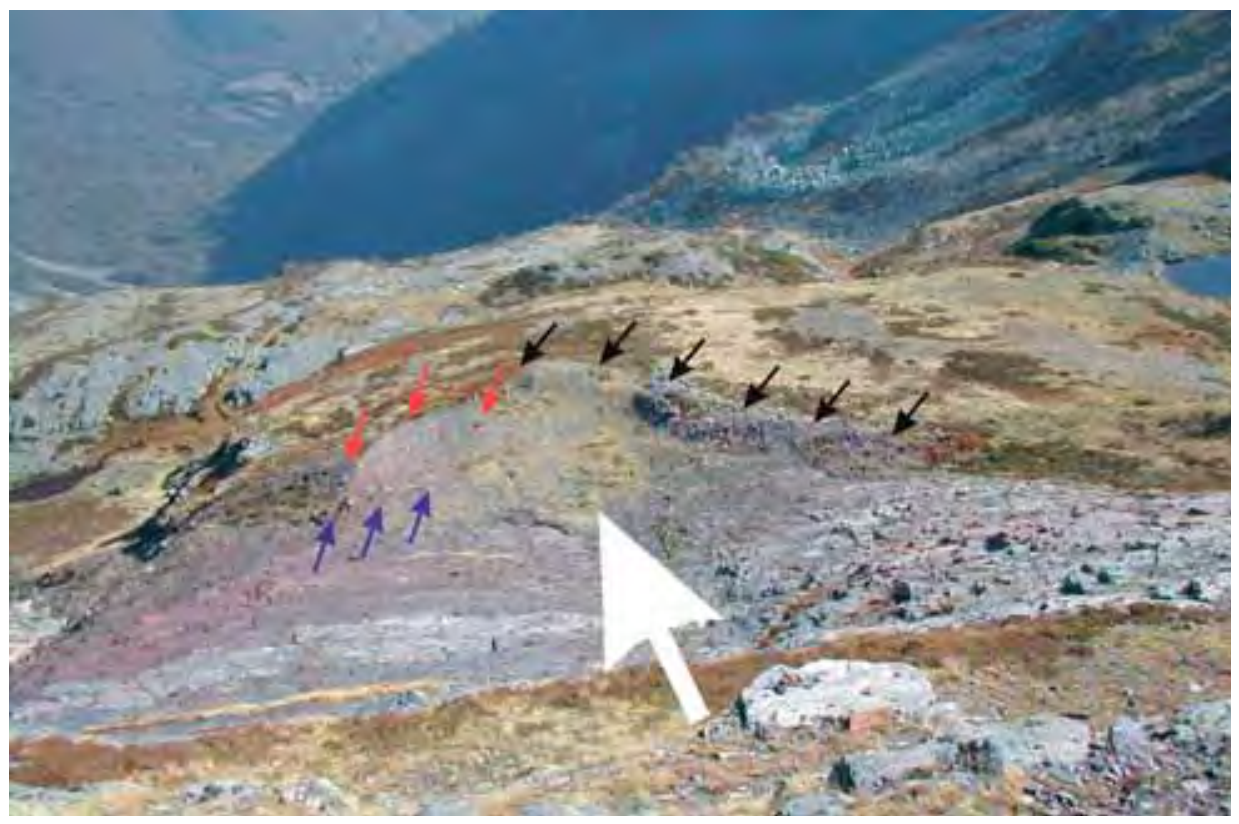

Figura 10. Morrenas de nevero frontolaterales (flechas negras) y frontales (flechas rojas y azules). La flecha blanca indica la dirección y el sentido del desplazamiento del manto nivoso. 
vegetación o ligeramente colonizadas por especies herbáceas. Por el contrario las caras exteriores, protegidas de la acción de empuje, han sido densamente colonizadas por Calluna vulgaris, Vaccinium uliginosum y Juniperus communis.

\section{Discusión}

La actividad geomorfológica observada pone de manifiesto la capacidad erosiva de la nieve, así como su competencia para movilizar material. Cabe preguntarse si esta actividad es el producto de un movimiento en masa rápido del manto nivoso (tipo avalancha de fondo), lento (como el deslizamiento nival o la nivoreptación), o bien una mezcla de ambos.

Las avalanchas de fondo se desencadenan en zonas concretas como los canales rocosos, que acumulan grandes espesores de nieve y sólo en años muy nivosos afectan a los sectores inferiores de la vertiente. Suelen producirse al comienzo de la primavera, en un único evento. Sus efectos morfológicos comprenden el arranque de material, la abrasión del substrato y la formación y modificación de microcrestas y morrenas de nevero.

Sin embargo, también se han observado estrías frescas y marcas de abrasión del año en sectores que no han sufrido avalanchas. En el caso concreto de las superficies pulidas, resulta problemático atribuir su génesis exclusivamente a la acción de las avalanchas de fondo. Muchas superficies que experimentan abrasión activa no son barridas por avalanchas todos los años. Parece lógico pensar en la existencia de un movimiento en masa lento, continuado a lo largo de buena parte del invierno, que explique la abrasión y movilización de material en estos sectores.

Los mantos nivosos que experimentan movimientos en masa lentos pueden realizar una notable labor geomorfológica. Costin et al. (1964) describieron la acción erosiva de un nevero semipermanente en Mount Twynam (Snowy Mountains, Australia), caracterizada por la abrasión de superficies rocosas y el arranque y movilización de fragmentos del substrato, atribuyéndola a la nivoreptación. Para el mismo nevero Costin et al. (1973) estimaron presiones basales de $11,6 \mathrm{~kg} \mathrm{~cm}^{-2}$, que llegaban a alcanzar valores extremos de $38,7 \mathrm{~kg} \mathrm{~cm}^{-2}$ en años particularmente nivosos. Según estos autores los rangos de presión basal estimados, resultaban suficientes para explicar la actividad erosiva y el transporte de clastos realizados por el nevero. Por su parte Shakesby et al. (1999) describieron la formación de pequeñas crestas y morrenas de nevero por el empuje de neveros semipermanentes que experimentaban deslizamiento basal y se desplazaban sobre substratos deformables.

Los dos tipos de movimiento en masa lento que pueden afectar a un manto nivoso depositado sobre una pendiente son la nivoreptación y el deslizamiento nival (Mathews y Mackay, 1975). La nivoreptación es un movimiento producido como consecuencia de la deformación interna de la nieve, que comprende el asentamiento vertical por gravedad del manto nivoso así como su cizallamiento interno, paralelo a la superficie del substrato. Por su parte, el deslizamiento nival consiste en el desplazamiento del manto 
nivoso como un todo, resbalando sobre la superficie del substrato (Mathews y Mackay, 1975). Su repercusión geomorfológica es considerable, ya que confiere una gran fuerza de empuje basal al manto nivoso.

El deslizamiento se produce preferentemente sobre superficies rocosas desnudas, con pendientes superiores a $15^{\circ}$ y siempre que la temperatura de la interfase nieve-substrato se sitúe en el entorno de los $0{ }^{\circ} \mathrm{C}$, permitiendo de esta forma la presencia de agua líquida a modo de film lubricante entre el substrato y el manto nivoso (McClung et al., 1994; Clarke y McClung, 1999). Las mediciones realizadas por Clarke y McClung (1999) revelan que el deslizamiento puede producirse a lo largo del invierno y la primavera. Los desplazamientos medios diarios son de rango milimétrico. Estos autores señalan además que el deslizamiento nival está asociado con las avalanchas de fondo, frecuentemente desencadenadas tras períodos de deslizamientos rápidos.

Tanto la vertiente estudiada como el manto nivoso reúnen las condiciones necesarias para el deslizamiento: substrato rocoso desnudo; pendiente general superior a $15^{\circ}$, e interfase substrato-manto nivoso a una temperatura de $0{ }^{\circ} \mathrm{C}$. Además, ciertos indicios de desplazamiento observados en el campo, como las grietas de tensión y los abombamientos superficiales en el manto nivoso, parecen apuntar su presencia.

Por tanto podemos considerar que la actividad geomorfológica descrita es el producto de la acción de empuje combinada de las avalanchas de fondo y el deslizamiento nival. Sin embargo, no es posible con los datos disponibles, diferenciar la aportación de ambos tipos de movimiento a la génesis de determinadas formas como las estrías o las superficies pulidas.

\section{Conclusiones}

Las observaciones realizadas en el entorno del Pico Cuiña evidencian la capacidad del manto nivoso estacional para erosionar significativamente una vertiente rocosa, mediante procesos básicos de arranque y abrasión, originando microformas como estrías, acanaladuras y fracturas arqueadas. La nieve muestra también competencia para transportar el material desalojado hacia la base de la vertiente y elaborar formas de acumulación características como microcrestas y morrenas de nevero.

La fuerza de empuje desarrollada por el manto nivoso se debe, presumiblemente, a una combinación de movimientos en masa lentos y rápidos. Tanto las características de la vertiente (rugosidad superficial y pendiente general), como el régimen térmico basal del manto nivoso, permiten la existencia de un movimiento lento como el deslizamiento nival, que podría actuar durante todo el invierno. Un incremento en las tasas de deslizamiento desencadenaría avalanchas de fondo a comienzos de la primavera.

Resulta necesario obtener más información, mediante monitorizaciones de campo, sobre los movimientos en masa lentos que afectan al manto nivoso, con objeto de determinar su repercusión geomorfológica individual, diferenciándola de la de las avalanchas de fondo. 


\section{Agradecimientos}

Este trabajo ha sido financiado a través de los proyectos de investigación REN200303292, concedido por la Dirección General de Investigación del Ministerio de Ciencia y Tecnología, y PGIDIT06PXIB239226PR, subvencionado por la Consellería de Innovación, Industria e Comercio de la Xunta de Galicia.

\section{Referencias bibliográficas}

Clarke, J., McClung, D. (1999). Full-depth avalanche occurrences caused by snow gliding, Coquihalla, British Columbia, Canada. Journal of Glaciology, 45: 539-546.

Costin, A. B., Jennings, J. N., Bautovich, B. C., Wimbush, D. J. (1973). Forces developed by snowpatch action, Mt. Twynam, Snowy Mountains, Australia. Arctic and Alpine Research, 5: 121-126.

Costin, A. B., Jennings, J. N., Black, H. P., Thom, B. G. (1964). Snow action on Mount Twynam, Snowy Mountains, Australia. Journal of Glaciology, 5: 219-228.

Mathews, W. H., Mackay, J. R. (1975). Snow creep: its engineering problems and some techniques and results of its investigation. Canadian Geotechnical Journal, 12: $187-198$.

McClung, D. M., Walker, S., Golley, W. (1994). Characteristics of snow gliding on rock. Annals of Glaciology, 19: 97-103.

Penas Merino, A., García González, M. E., Herrero Cembranos, L., Puente GarCÍA, E. (1995). Pisos bioclimáticos: Ombrotipos. En: Atlas del medio natural de la provincia de León (García Cortés, A., Gallego Valcarce, E. y Barettino Fraile, D., Dirs.). Instituto Tecnológico Geominero de España, pp. 23-24, Madrid.

Pulgar, J. A., Bastida, F., Marcos, A., Pérez Estaun, A., Galán, J., Vargas, I. (1978). Memoria del Mapa Geológico de España, E. 1:50.000, hoja $n^{\circ} 100$ (Degaña). Instituto Geológico y Minero de España, 27 pp., Madrid.

Shakesby, R. A., Matthews, J. A., McEwen, L. J., Berrisford, M. S. (1999). Snow-push processes in pronival (protalus) rampart formation: geomorphological evidence from Smorbotn, Romsdalsalpane, Southern Norway. Geografiska Annaler, 81: 31-45.

VALCÁRCEl DíAZ, M. (1998). Evolución geomorfológica y dinámica de las vertientes en el NE de Galicia. Importancia de los procesos de origen frío en un sector de las montañas lucenses. Tesis doctoral. Universidade de Santiago de Compostela, 496 pp, Santiago de Compostela.

VAlCÁRcel DíAz, M., Pérez Alberti, A. (2002). La glaciación finipleistocena en el sector noroccidental de las montañas leonesas: la Sierra de Ancares. En: El modelado de origen glaciar en las montañas leonesas (Redondo Vega, J.M., Gómez Villar, A., González Gutiérrez, R.B. y Carrera Gómez, P., Coords.). Universidad de León, pp. 67-102, León. 